\title{
ANALISIS PENGARUH WORK LIFE BALANCE, GAYA KEPEMIMPINAN, DAN LINGKUNGAN KERJA TERHADAP KEINGINAN PINDAH KERJA PADA GENERASI MILENIAL
}

\author{
Axamina Christi Unawekla \\ Program Studi Magister Manajemen Universitas Tarumanagara \\ christyunawekla@gmail.com \\ Riris Loisa \\ Program Studi Magister Manajemen Universitas Tarumanagara
}

Masuk : 05-12-2020, revisi : 20-12-2020, diterima untuk diterbitkan : 21-12-2020

\begin{abstract}
The purpose of this study is to examine the effect of work-life balance, leadership style, and work environment on turnover intentions in the millennial generation in Jakarta. This research is a descriptive quantitative study, using a purposive sampling technique with a sample of 105 respondents. The data were analyzed using multiple linear regression analysis techniques using SPSS version 26. The results of this study indicate that the work-life balance variable does not affect the turnover intention for the millennial generation in Jakarta. The leadership style variable has a negative and significant effect on the turnover intention of the millennial generation in Jakarta. Work environment variables have a negative and significant effect on the turnover intention of the millennial generation in Jakarta. Work-life balance, leadership style, and environment variables simultaneously influence turnover intention for the millennial generation in Jakarta. Work-life balance, leadership style, and work environment contributed 63.8 percent to turnover intention.
\end{abstract}

Keywords: Work Life Balance, Leadership Style, Work Environment, Turnover Intention

\begin{abstract}
Abstrak: Tujuan dari penelitian ini adalah untuk menguji pengaruh work life balance, gaya kepemimpinan dan lingkungan kerja terhadap keinginan pindah kerja pada generasi milenial di Jakarta. Penelitian ini adalah penelitian kuantitatif deskriptif, menggunakan teknik purposive sampling dengan sampel berjumlah 105 responden. Data dianalisis dengan teknik analisis regresi linier berganda dengan menggunakan SPSS versi 26. Hasil dari penelitian ini menunjukkan variabel work life balance tidak berpengaruh terhadap keinginan pindah kerja generasi milenial di Jakarta. Variabel gaya kepemimpinan berpengaruh negatif dan signifikan terhadap keinginan pindah kerja generasi milenial di Jakarta. Variabel lingkungan kerja berpengaruh negatif dan signifikan terhadap keinginan pindah kerja generasi milenial di Jakarta. Variabel work life balance, gaya kepemimpinan, dan lingkungan kerja secara bersamasama secara simultan berpengaruh terhadap keinginan pindah kerja. Work life balance, gaya kepemimpinan, dan lingkungan kerja memberikan kontribusi sebesar 63,8 persen terhadap keinginan pindah kerja.
\end{abstract}

Kata Kunci: Work Life Balance, Gaya Kepemimpinan, Lingkungan Kerja, Keinginan Pindah Kerja

\section{PENDAHULUAN}

Keberlangsungan kehidupan perusahaan ditunjang oleh sumber daya manusia yang berkualitas. Karyawan adalah bagian penting perusahaan yang harus dikelola dengan baik oleh perusahaan. Pada era globalisasi saat ini, perusahaan dihadapkan dengan tantangan masuknya generasi milenial pada dunia kerja. Generasi milenial ini berbeda dari generasi lainnya dari segi pemikiran dan keinginan mereka. Menurut Strauss dan Howe (2000), generasi milenial adalah generasi yang lahir pada tahun 1982-2000 atau berusia 20-38 tahun. Generasi milenial 
menginginkan pemimpin yang berbagi ilmu kepada mereka, bukan hanya sekedar memerintah dan mengontrol saja. Dalam dunia kerja mereka lebih memilih untuk mencari kesempatan untuk berkembang dengan menambah relasi, menambah sudut pandang baru dan mempelajari hal baru (Budiarti et al., 2018). Work life balance sangat penting bagi generasi milenial dalam hal keterikatan kerja. Dengan adanya keseimbangan antara pekerjaan dan kehidupan pribadi karyawan, maka kinerja dan produktifitas karyawan dapat meningkat dan terjaga dengan baik. Oleh karena itu perusahaan harus membuat kebijakan atau aturan yang mendukung keseimbangan kedua hal ini. Keberlangsungan perusahaan juga didukung dengan adanya pemimpin yang berkualitas, dan mengayomi bahwahannya. Gaya kepemimpinan ini juga memiliki pengaruh terhadap keterikatan karyawan dengan perusahaan. Selain gaya kepemimpinan, lingkungan kerja juga penting bagi keberlangsungan perusahaan. Lingkungan kerja adalah seluruh aspek dalam perusahaan yang dapat mempengaruhi kualitas kerja seorang karyawan, seperti hubungan dengan rekan kerja, hubungan dengan atasan, kelengkapan fasilitas penunjang pekerjaan, fasilitas dari dan ke tempat kerja serta kondisi-kondisi fisik dalam ruang kerja.

\section{Tujuan Penelitian}

Tujuan penelitian ini adalah sebagai berikut:

1. Menguji pengaruh work life balance terhadap keinginan pindah kerja.

2. Menguji pengaruh gaya kepemimpinan terhadap keinginan pindah kerja.

3. Menguji pengaruh lingkungan kerja terhadap keinginan pindah kerja.

4. Menguji pengaruh antara work life balance, gaya kepemimpinan, dan lingkungan kerja secara bersama-sama terhadap keinginan pindah kerja.

\section{TINJAUAN PUSTAKA}

Menurut Werther dan Davis dalam Sutrisno (2009), sumber daya manusia adalah pegawai yang siap, mampu dan siaga dalam mencapai tujuan-tujuan organisasi. Munculnya kebutuhan untuk membantu perusahaan untuk mencapai tujuannya merupakan profesionalisme dalam bekerja. Menurut Handayani et al. (2015), work life balance adalah kondisi dimana individu merasa terikat dan puas terhadap kehidupan pekerjaan dan kehidupan pribadi atau keluarganya serta mampu menyeimbangkan tuntutan diantara keduanya. Menurut Sunyoto (2013), kepemimpinan adalah sebagai suatu proses untuk mempengaruhi aktivitas dari seseorang atau kelompok untuk mencapai tujuan dalam organisasi. Menurut Sedarmayanti (2013), lingkungan kerja adalah suatu tempat yang berisikan fasilitas-fasilitas yang mendukung untuk mencapai visi dan misi perusahaan. Abdillah (2012) menyatakan intensi pindah kerja merupakan suatu posisi dimana karyawan memiliki keinginan atau niat untuk mencari suatu pekerjaan lain sebagai alternatif di organisasi yang berbeda. Kerangka pemikiran menurut peneliti tergambar sebagai berikut:

\section{Gambar 1}

Kerangka Pemikiran

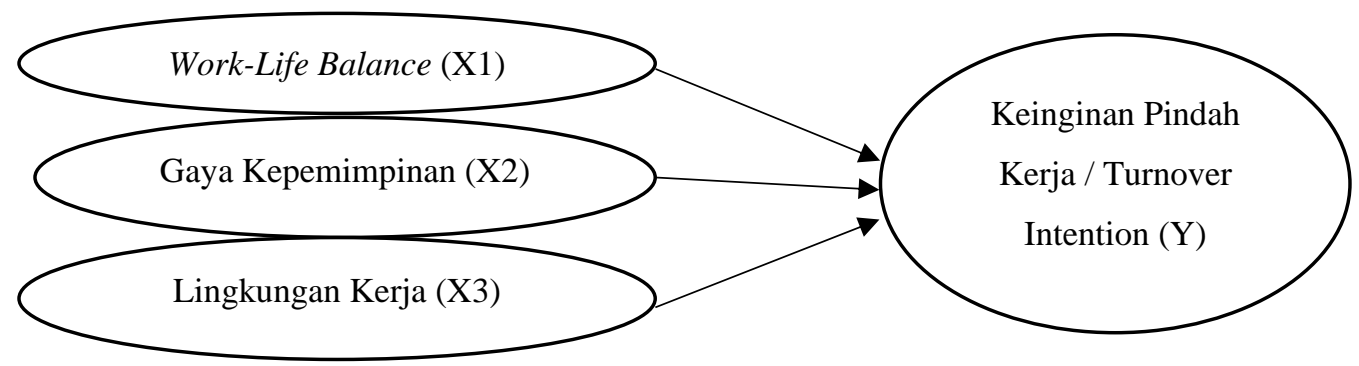

Hipotesis dalam penelitian ini yaitu :

H1 : Adanya pengaruh antara work life balance terhadap keinginan pindah kerja.

H2 : Adanya pengaruh gaya kepemimpinan terhadap keinginan pindah kerja.

H3 : Adanya pengaruh antara lingkungan kerja terhadap keinginan pindah kerja. 
H4 : Adanya pengaruh antara work life balance, gaya kepemimpinan, lingkungan kerja secara bersama-sama terhadap keinginan pindah kerja.

\section{METODOLOGI PENELITIAN}

Penelitian ini adalah penelitian kuantitatif deskriptif dengan sampel dari populasi generasi milenial yang berusia 20-38 tahun yang bekerja pada perusahaan swasta maupun pemerintah yang ada di Jakarta. Teknik dalam penelitian ini adalah teknik purposive sampling, dengan sumber data primer. Pengumpulan data primer dilakukan dengan alat kuesioner dengan pengukuran variabel menggunakan skala likert yang akan disebarkan secara online kepada 105 responden. Aplikasi yang digunakan dalam penelitian ini adalah Statistical Program for Social Science (SPSS) versi 26 dengan menggunakan analisis regresi linear berganda.

Uji validitas dalam penelitian ini menggunakan Bivariate Pearson (Product Moment Pearson Correlation. Item pernyataan valid jika memenuhi syarat nilai $r$ hitung $\geq \mathrm{r}$ tabel $(0,195)$. Dasar pengambilan keputusan lain apakah item pertanyaan valid, dapat dengan syarat nilai Sig. (2-tailed) $\leq$ 0,05 dan Pearson Correlationnya bernilai positif. Metode Cronbach's Alpha digunakan dalam penelitian ini untuk pengujian reliabilitas dengan standar nilai alpha $\geq$ 0.70. Uji normalitas dilakukan dengan pendekatan Kolmogorow-Smirnov yaitu data dikatakan berdistribusi dengan normal jika tidak terdapat perbedaan yang signifikan antara data dalam penelitian yang diuji dengan data normal baku, jika nilai signifikansi $\geq 0,05$ (Ghozali, 2015). Nilai toleransi $\geq 0,01$ atau VIF $\leq 10$ berarti tidak ada multikolinearitas dalam model regresi penelitian ini. Jika data tidak berpola, dan menyebar secara merata pada atas dan bawah, dan tidak berkumpul pada atas dan bawah saja maka artinya tidak terdapat heteroskedastisitas dalam penelitian ini (Ghozali, 2015). Untuk uji parsial/t-test yaitu dengan melihat nilai thitung (hasil output SPSS) $\leq \mathrm{t}$ tabel $(1,983)$, maka variabel bebas $(\mathrm{X})$ secara sebagian tidak berpengaruh terhadap variabel terikat $(Y)$. Jika nilai signifikansi menunjukkan nilai $\geq 0,05$, artinya tidak ada pengaruh antara variabel bebas (X) dengan variabel terikat (Y). Jika sebaliknya, maka hipotesis penelitian diterima, artinya ada pengaruh antara variabel bebas dengan variabel terikat. Dalam Uji F (Simultan), hipotesis diterima jika nilai F hitung $\geq F$ tabel $(2,69)$ dan nilai $\mathrm{f} \leq 0,05$, artinya variabel bebas berpengaruh secara bersama-sama terhadap variabel terikat. Menurut Ghozali (2015), untuk mengetahui kemampuan variabel-variabel bebas dalam menerangkan variabel dependen dalam penelitian dilihat dari hasil output koefisien determinasi $\left(\mathrm{R}^{2}\right)$ atau $R$ Square.

\section{HASIL TEMUAN}

Berdasarkan hasil penelitian kepada 105 orang responden melalui kuesioner yang disebarkan, responden perempuan sebanyak 73 orang, responden laki-laki berjumlah 32 orang. Mayoritas responden berusia antara 20-25 tahun sebanyak 50 orang, kemudian responden berusia antara 26-30 tahun sebanyak 43 orang dan responden berusia antara 31-38 tahun sebanyak 12 orang. Sebanyak 88 orang pendidikan S1, diikuti dengan pendidikan D3 dan SMA sebanyak 7 orang, dan sebanyak 3 orang dengan pendidikan S2. Selanjutnya, didapatkan hasil responden terbanyak dalam penelitian ini bekerja pada perusahaan swasta sebanyak 96 orang dan hanya sebanyak 9 orang yang bekerja pada pemerintahan di Jakarta. Responden pada penelitian ini memiliki pendapatan < Rp. 2.000 .000 sebanyak 7 orang, pendapatan antara Rp. 3.000.000 - Rp.4.000.000 sebanyak 44 orang, 35 orang berpendapatan antara Rp. 5.000.000 Rp.7.000.000 dan 19 orang dengan pendapatan > Rp.7.000.000. 


\section{Tabel 1}

Uji Validitas

\begin{tabular}{|c|c|c|c|c|c|c|c|}
\hline $\begin{array}{c}\text { Item } \\
\text { Pernyataan }\end{array}$ & $\begin{array}{c}\text { r Hitung } \\
\text { X1 }\end{array}$ & $\begin{array}{c}\text { r Hitung } \\
\text { X2 }\end{array}$ & $\begin{array}{c}\text { r Hitung } \\
\text { X3 }\end{array}$ & $\begin{array}{c}\text { r Hitung } \\
\text { Y }\end{array}$ & $\begin{array}{c}\text { Sig (2 } \\
\text { tailed) }\end{array}$ & r Tabel & Keterangan \\
\hline 1 & $0.431^{* *}$ & $0.350^{* *}$ & $0.825^{* *}$ & $0.835^{* *}$ & .000 & 0,195 & Valid \\
\hline 2 & $0.568^{* *}$ & $0.416^{* *}$ & $0.739^{* *}$ & $0.695^{* *}$ & .000 & 0,195 & Valid \\
\hline 3 & $0.620^{* *}$ & $0.802^{* *}$ & $0.868^{* *}$ & $0.574^{* *}$ & .000 & 0,195 & Valid \\
\hline 4 & $0.259^{* *}$ & $0.641^{* *}$ & $0.818^{* *}$ & $0.808^{* *}$ & .000 & 0,195 & Valid \\
\hline 5 & $0.289^{* *}$ & $0.857^{* *}$ & $0.819^{* *}$ & $0.728^{* *}$ & .000 & 0,195 & Valid \\
\hline 6 & $0.616^{* *}$ & $0.847^{* *}$ & $0.807^{* *}$ & & .000 & 0,195 & Valid \\
\hline 7 & $0.558^{* *}$ & $0.859^{* *}$ & $0.689^{* *}$ & & .000 & 0,195 & Valid \\
\hline 8 & $0.739^{* *}$ & $0.828^{* *}$ & $0.656^{* *}$ & & .000 & 0,195 & Valid \\
\hline 9 & $0.597^{* *}$ & $0.766^{* *}$ & $0.671^{* *}$ & & .000 & 0,195 & Valid \\
\hline 10 & $0.732^{* *}$ & & $0.672^{* *}$ & & .000 & 0,195 & Valid \\
\hline 11 & & & $0.798^{* *}$ & & .000 & 0,195 & Valid \\
\hline
\end{tabular}

\section{Tabel 2}

\section{Uji Reliabilitas}

\begin{tabular}{|c|c|c|}
\hline Variabel & Cronbach's Alpha & Keterangan \\
\hline Work Life Balance (X1) & 0.731 & Reliabel \\
\hline Gaya Kepemimpinan (X2) & 0.884 & Reliabel \\
\hline Lingkungan Kerja (X3) & 0.925 & Reliabel \\
\hline Keinginan Pindah Kerja (Y) & 0.827 & Reliabel \\
\hline
\end{tabular}

Tabel 3

One-Sample Kolmogorov-Smirnov Test

\begin{tabular}{|c|c|c|}
\hline & & Unstandardized Residual \\
\hline \multicolumn{2}{|l|}{$\mathrm{N}$} & 105 \\
\hline \multirow{2}{*}{ Normal Parameters ${ }^{\mathrm{a}, \mathrm{b}}$} & Mean & 0 \\
\hline & Std. Deviation & 2.23829724 \\
\hline \multirow{3}{*}{ Most Extreme Differences } & Absolute & 0.078 \\
\hline & Positive & 0.058 \\
\hline & Negative & -0.078 \\
\hline \multicolumn{2}{|c|}{ Test Statistic } & 0.078 \\
\hline \multicolumn{2}{|c|}{ Asymp. Sig. (2-tailed) } & $.120^{\mathrm{c}}$ \\
\hline
\end{tabular}

a. Test distribution is Normal.

b. Calculated from data.

c. Lilliefors Significance Correction.

\section{Tabel 4}

Uji Multikolinieritas

\begin{tabular}{|l|l|l|l|l|}
\hline \multirow{2}{*}{ No } & \multirow{2}{*}{ Variabel } & \multicolumn{2}{|l|}{ Collinearity Statistics } & \multirow{2}{*}{ Keterangan } \\
\cline { 3 - 4 } & & Tolerance & VIF & \\
\hline 1 & Work Life Balance $(\mathrm{X} 1)$ & 0.638 & 1.568 & Tidak adanya Multikolinearitas \\
\hline 2 & Gaya Kepemimpinan $(\mathrm{X} 2)$ & 0.766 & 1.306 & Tidak adanya Multikolinearitas \\
\hline 3 & Lingkungan Kerja (X3) & 0.597 & 1.676 & Tidak adanya Multikolinearitas \\
\hline
\end{tabular}

\section{Gambar 2}

Uji Heteroskedastisitas

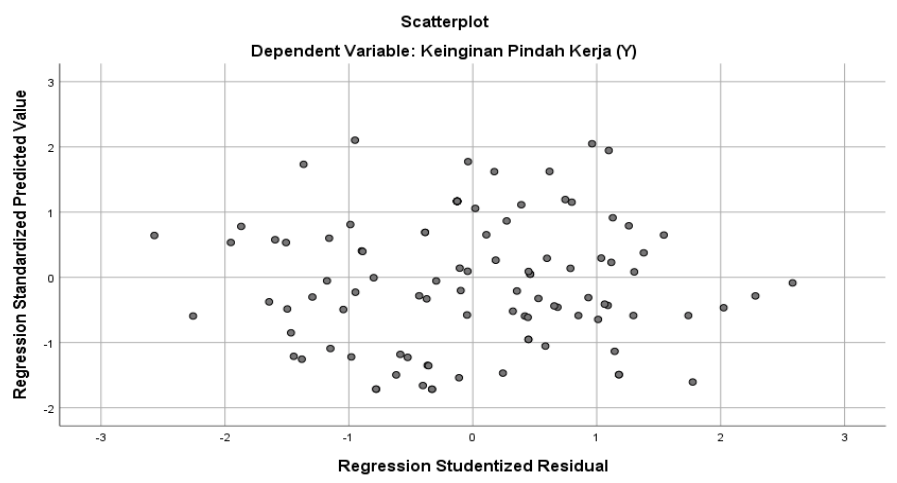

Berdasarkan gambar 2, tidak terdapat heteroskedastisitas dalam regresi penelitian ini. 
Tabel 6

Uji Regresi Linear Berganda

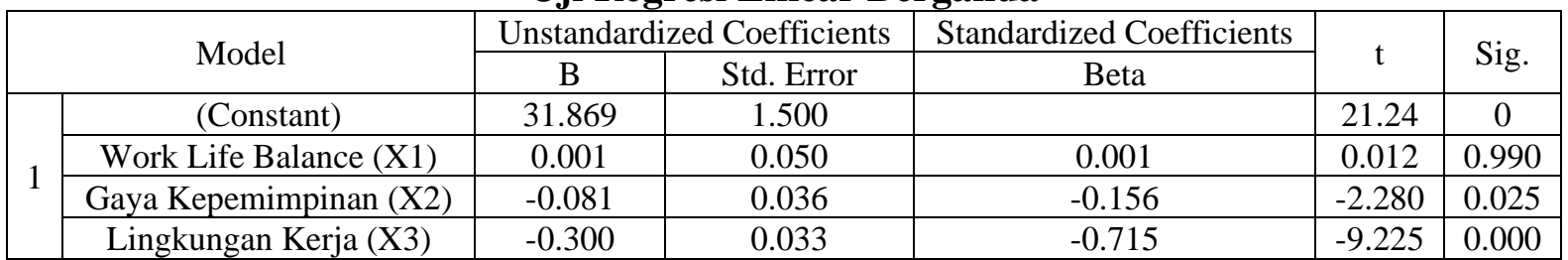

a. Dependent Variable: Keinginan Pindah Kerja (Y)

Berdasarkan tabel 6, dapat dirumuskan persamaan regresi untuk model regresi penelitian ini sebagai berikut: Keinginan Pindah Kerja = 31,869 + 0,001 WLB - 0,081 GK - 0,300 LK.

Uji Parsial / T-Test

Uji Hipotesis Pertama (H1). Berdasarkan tabel diatas, nilai t hitung variabel work life balance (X1) 0,012 < 1,983, nilai signifikansi 0,990>0,05 berarti H1 di tolak. Variabel work life balance tidak berpengaruh secara parsial terhadap keinginan pindah kerja (Y).

Uji Hipotesis Kedua (H2). Berdasarkan tabel diatas, nilai t hitung variabel gaya kemimpinan (X2) -2,280 > 1,938, nilai signifikansi 0,025 < 0,05, berarti $\mathrm{H} 2$ di terima. Variabel gaya kepemimpinan berpengaruh negatif dan signifikan secara parsial terhadap keinginan pindah kerja (Y).

Uji Hipotesis Ketiga (H3). Berdasarkan tabel diatas, nilai t hitung variabel lingkungan kerja (X3) -9,225 > 1,938, nilai signifikansi $0,000<0,05$ berarti H3 di terima. Variabel lingkungan kerja berpengaruh negatif dan signifikan secara parsial terhadap keinginan pindah kerja (Y).

Tabel 7

Uji F (Simultan) Output ANOVA ${ }^{\mathrm{a}}$

\begin{tabular}{|c|c|c|c|c|c|c|}
\hline \multicolumn{2}{|c|}{ Model } & Sum of Squares & df & Mean Square & F & Sig. \\
\hline \multirow{3}{*}{1} & Regression & 916.525 & 3 & 305.508 & 59.221 & $.000^{\mathrm{b}}$ \\
\cline { 2 - 7 } & Residual & 521.037 & 101 & 5.159 & & \\
\cline { 2 - 7 } & Total & 1437.562 & 104 & & & \\
\hline
\end{tabular}

a. Dependent Variable: Keinginan Pindah Kerja (Y)

b. Predictors: (Constant), Lingkungan Kerja (X3), Gaya Kepemimpinan (X2), Work Life Balance (X1)

Uji Hipotesis Keempat (H4). Berdasarkan tabel diatas, didapatkan nilai signifikansi $0.000<0,05$, nilai F hitung 59,221 > 2,69 berarti $\mathrm{H} 4$ diterima. Variabel work life balance (X1), gaya kepemimpinan (X2), dan lingkungan kerja (X3) secara bersama-sama simultan berpengaruh terhadap keinginan pindah kerja (Y).

\section{Tabel 8}

Nilai Koefisien Determinasi $\left(\mathbf{R}^{2}\right)$ Output Model Summary ${ }^{b}$

\begin{tabular}{|c|c|c|c|c|}
\hline Model & R & R Square & Adjusted R Square & Std. Error of the Estimate \\
\hline 1 & $0.798^{\mathrm{a}}$ & 0.638 & 0.627 & 2.2713 \\
\hline
\end{tabular}

Predictors: (Constant), Lingkungan Kerja (X3), Gaya Kepemimpinan (X2), Work Life Balance (X1) Dependent Variable: Keinginan Pindah Kerja (Y)

Berdasarkan tabel diatas, menunjukkan nilai $R$ Square sebesar 0,638 atau sebesar 63,8 persen kontribusi pengaruh variabel work life balance, gaya kepemimpinan, dan lingkungan kerja terhadap keinginan pindah kerja. Sisanya sebesar 36,2 persen sisanya dijelaskan oleh variabel-variabel lain (komitmen organisasi, kepuasan kerja, dan budaya organisasi) diluar dari persamaan regresi ini atau variabel yang tidak diteliti dalam penelitian ini.

\section{KESIMPULAN}

1. Variabel work life balance tidak berpengaruh terhadap keinginan pindah kerja generasi milenial di Jakarta.

2. Variabel gaya kepemimpinan berpengaruh negatif dan signifikan terhadap keinginan pindah kerja generasi milenial di Jakarta. 
3. Variabel lingkungan kerja berpengaruh negatif dan signifikan terhadap keinginan pindah kerja generasi milenial di Jakarta.

4. Variabel work life balance, gaya kepemimpinan, dan lingkungan kerja secara bersamasama secara simultan berpengaruh terhadap keinginan pindah kerja generasi milenial di Jakarta.

\section{DAFTAR PUSTAKA}

Abdillah, F. (2012). Hubungan kohesivitas kelompok dengan intensi turnover pada karyawan. Journal of Social and Industrial Psychology, 1(2), 52-58. https://journal.unnes.ac.id/sju/index.php/sip/article/view/2645

Budiarti, I., Susianto, Y., P, W. P. A., Ayuni, S., Reagan, H. A., Larasaty, P., Setiyawati, N., Pratiwi, A. I., \& Saputri, V. G. (2018). Statistik gender tematik: Profil generasi milenial Indonesia (Badan Pusat Statistik (ed.)). Kementerian Pemberdayaan Perempuan dan Perlindungan Anak.

Ghozali, I. (2015). Aplikasi analisis multivariate dengan program IBM SPSS 23. Badan Penerbit Universitas Diponegoro.

Handayani, A., Afiati, T., \& Adiyanti, M. G. (2015). Studi eksplorasi makna keseimbangan kerja keluarga pada ibu bekerja. Seminar Psikologi Dan Kemanusiaan, 30-36. http://mpsi.umm.ac.id/files/file/30-36 Arri Handayani.pdf

Sedarmayanti. (2013). Tata kerja dan produktifitas kerja. Mandar Maju.

Strauss, W., \& Howe, N. (2000). Millenial rising: The next great generation. Knopf Doubleday Publishing Group.

Sunyoto, D. (2013). Perilaku organisasional (1st ed.). CAPS.

Sutrisno, E. (2009). Manajemen sumber daya manusia. Kencana Prenada Media Group. 